\title{
SLC39A13-related spondylodysplastic Ehlers-Danlos syndrome
}

INSERM

\section{Source}

INSERM. (1999). Orphanet: an online rare disease and orphan drug data base. SLC39A13related spondylodysplastic Ehlers-Danlos syndrome. ORPHA:157965

Ehlers-Danlos syndrome, spondylocheirodysplastic type is a subtype of Ehlers-Danlos syndrome characterized by skeletal dysplasia comprising platyspondyly with moderate short stature, osteopenia and widened metaphyses, in addition to hyperextensible, thin, easily bruised skin, hypermobility of small joints with tendency to contractures, prominent eyes with bluish sclerae, wrinkled palms, atrophy of the thenar muscle and tapering fingers. 